Article

\title{
Optimal Remanufacturing Certification Contracts in the Electrical and Electronic Industry
}

\author{
Huihui Liu ${ }^{1}$, Xiaohang Yue ${ }^{2}$, Hui Ding ${ }^{3}$ and G. Keong Leong ${ }^{4, *}$ \\ 1 Academy of Chinese Energy Strategy, China University of Petroleum, Beijing 102200, China; \\ liuhuihui@cup.edu.cn \\ 2 Lubar School of Business, University of Wisconsin-Milwaukee, Milwaukee, WI 53211, USA; xyue@uwm.edu \\ 3 School of Foreign Languages, China University of Petroleum, Beijing 102200, China; english@cup.edu.cn \\ 4 College of Business Administration \& Public Policy, California State University Dominguez Hills, Carson, \\ CA 90747, USA \\ * Correspondence: gkleong@csudh.edu; Tel.: +1-310-243-2178; Fax: +1-310-516-3664
}

Academic Editors: Xiang Li, Jian Zhou, Hua Ke and Xiangfeng Yang

Received: 6 February 2017; Accepted: 24 March 2017; Published: 30 March 2017

\begin{abstract}
While remanufacturing is highly encouraged worldwide, some original equipment manufacturers (OEMs) in the electrical and electronics industry are still not willing to embrace remanufacturing, for fear of expensive investment or the cannibalization of existing products. Meanwhile, third-party remanufacturers' (TPRs) remanufactured products are developing quickly. Due to quality reasons, consumers usually have a higher preference for OEM-certified remanufactured products than uncertified ones. As such, remanufacturing certification has become a strategy that OEMs can use to benefit from product remanufacturing. Our paper focuses on the remanufacturing certification contract between an OEM and a TPR. Once certified, the TPR makes payments to the OEM. These payment terms will affect their enthusiasm for participating in remanufacturing certification. By establishing game models among an OEM, a certified TPR, and an uncertified TPR, our paper explores three certification contracts, namely, the lump-sum payment, profit-sharing payment, and piece-rate payment. We identify the conditions for the OEM and certified TPR to reach a win-win outcome. Our results show that when TPRs have a high profit margin and there is no significant difference in consumers' preferences between certified and non-certified remanufacturing channels, the profit-sharing payment contract yields the highest profit; otherwise, the piece-rate payment contract is best for the OEM.
\end{abstract}

Keywords: electrical and electronics industry; remanufacturing; certification; third-party remanufacturer; lump-sum payment contract; profit-sharing payment contract; piece-rate payment contract

\section{Introduction}

With the increasing awareness of sustainable manufacturing, remanufacturing has been growing quickly in the electrical and electronic industry, due to environmental concerns, government legislation, corporate social responsibility, and sustainable competitiveness [1,2]. Remanufacturing is the industrial process of restoring used products into those exhibiting an as-new condition [3,4]. Modules disassembled from returned products are kept, replaced, or restored, and then reassembled into remanufactured products [5]. The promotion of the remanufacturing industry has become an important issue worldwide. This is because discarded e-products have both the attributes of a valuable resource and a potential pollutant. The recycling and reusing of e-products is a highly profitable business, while unregulated disposal may cause severe environmental pollution due to the components of harmful heavy metals [6]. To promote environmentally friendly practices for the reuse of e-products, many countries have strict regulations based on the principal 
of extended producer responsibility (EPR), to encourage producers to engage in recycling and reusing [7]. However, even though remanufacturing may result in a reduction in the production cost $[1,4]$, many manufacturers are still not willing to embrace remanufacturing for fear of expensive investment in the fixed cost of remanufacturing or the internal cannibalization of the sales of new products [8]. Moreover, various uncertainties in the acquisition of products and recovery management also discourage manufacturers from entering into remanufacturing.

On the other hand, third party remanufactures (TPRs) thrive on the business of selling remanufactured products in the secondary market [9], which have posed a threat to the demand for new products [10]. The upgrading of e-products has led to the prosperity of the secondary market for remanufactured products. According to the U.S. International Trade Commission, the value of U.S. remanufactured production was about $\$ 43$ billion in 2011 [11]. However, because of the lack of uniform regulation, the secondary markets are comprised of both superior and poor quality e-products, from various remanufacturers. A lack of guarantee, control, or clear information about remanufacturing conditions has left consumers in doubt. It is observed that consumers are sensitive to the source of the remanufacturing work, and usually have a higher preference for manufacturers' or manufacturer-certified remanufactured products than uncertified products $[12,13]$.

Today, the trend is towards certifying TPRs by providing strict guidelines for the remanufacturing processes. A certified TPR will pay an agreed certification fee to an original equipment manufacturer $(\mathrm{OEM})$ and produce the remanufactured products under the OEM's specific standards. For example, Lenovo and HP provide certification to TPRs and implement a rigorous examination to ensure that they meet the technical requirements and quality control criteria, and that the remanufactured products will not damage the company's brand reputation [14,15]. Since March 2015, Apple Inc. has started a trade-in program for iPhones in China, in cooperation with the Foxconn Technology Group [16]. This collaboration certifies Foxconn to directly collect the older model iPhones and repair the devices according to stringent quality standards, before reselling the remanufactured ones. For OEMs, remanufacturing certification has several benefits. First, the certification payment will directly contribute to the OEM's profits. Second, certified TPRs' products are similar to OEMs' own low-level products, as opposed to those products from uncertified TPRs. Therefore, OEMs can benefit from price discrimination. Finally, OEMs do not have to directly engage in remanufacturing work and will be less pressured to invest in and manage a new business, and will thus be better able to focus on new product introductions and marketing.

In the strategy of remanufacturing certification, deciding on an optimal certification contract has become a big concern confronting OEMs. Certification contracts with an agreement on payment terms will affect whether OEMs can make a profit from the certification program, which further exerts an influence on OEMs' enthusiasm for participating in remanufacturing. This is a relatively new issue, without much previous research. In this paper, we examine how an OEM chooses an optimal certification contract for a TPR, when we have a competing TPR.

Based on the literature on cooperation contracts, we study three certification contracts, namely the lump-sum payment contract, the profit-sharing payment contract, and the piece-rate payment contract, described as follows:

(1) In the contract of lump-sum payment, a certified TPR pays a one-time certification fee to the OEM. Due to ease of implementation, the lump-sum contract form has been used for supply chain collaboration [17-19].

(2) In the contract of profit sharing, a certified TPR pays a certain percentage of its profit to the OEM as certification fees. This kind of contract form, along with wholesale pricing, has also been commonly used in supply chain collaboration [20,21].

(3) In the contract of piece-rate payment, a certified TPR pays a certification fee for each remanufactured product. This contract has been proposed by Oraiopoulos et al. [10] in the relicensing of some manufacturers. 
The remainder of this paper is organized as follows. We review the related literature in Section 2. In Section 3, we present the model setting and consider a price competition game between one OEM and two TPRs (one is certified and the other uncertified). Based on that, Sections 4-6 study three certification contracts and discuss the win-win conditions between the OEM and the certified TPR. In Section 7, we make numerical comparisons between the three contracts and analyze the optimal contract for the OEM. Finally, Section 8 provides the conclusions.

\section{Literature Review}

In recent years, remanufacturing has become more prevalent due to the high growth of the secondary product market [22,23]. Govindan et al. [24] and Kumar and Ramachandran [25] present a comprehensive review of research in this area. Our paper focuses on the cooperation and competitive relationship between an OEM, a certified TPR, and an uncertified TPR, in managing new and remanufactured products. Studies associated with our paper can be categorized into four categories: manufacturing and remanufacturing management; competitive impact of TPRs' remanufactured products on an OEM's new products; cooperation between an OEM and a TPR through remanufacturing certification; and certification contract selection between an OEM and a TPR.

Research in manufacturing and remanufacturing management mainly focuses on purchasing management [26-28], manufacturing planning [29-33], inventory control [27,34], and material planning [35-37]. For example, Mitra [26] examines how a monopolist firm manages the core supply in producing both new and remanufactured products. Bulmus et al. [29] study an OEM's acquisition decision of old products and the pricing of new and remanufactured products in one period. Van Der Laan et al. [34] explore production planning and inventory control in a hybrid system containing manufacturing and remanufacturing activities. Ferguson et al. [35] introduce the quality factor of returned products and study a tactical production-planning problem for remanufacturing. However, the above studies only consider the manufacturing activity of one firm.

Some literature considers TPRs' remanufacturing activities which compete with manufacturers' new products. Atasu et al. [1] point out that, confronted with the competition of TPRs, OEMs should engage in the remanufacturing process and use it as a marketing strategy to defend their market share through price discrimination. Ferrer and Swaminathan [12] characterize the competition between an OEM and a remanufacturer in multi-periods and indicate that the OEM's remanufactured products have a higher recognition than those from the remanufacturer in the market. Results show that when competition becomes intense, the OEM tends to remanufacture all returned products. In Wu [38], an OEM can set the interchangeability level to determine which products can be disassembled without force. Results show that this product-design strategy is effective for the OEM in competing with a remanufacturer. The above papers assume that an OEM carries out remanufacturing or competes with TPRs using product-design or pricing strategies, rather than managing the remanufacturing activities through cooperation with TPRs.

The literature on certification cooperation between an OEM and a TPR is limited. In Oraiopoulos et al. [10], because of software updates and copyrights, a TPR has to be relicensed by an OEM. This paper indicates that an OEM's control through mandatory certification could influence the growth of the secondary goods market. Zou et al. [39] compare two modes of outsourcing and authorization that OEMs could take to a TPR on remanufacturing branded or patented products. Hong et al. [40] study the technology licensing on patented products between a manufacturer who is the patent holder and a remanufacturer who is the licensee. Huang and Wang [41] assume that a manufacturer tends to cooperate with a distributor and a third party through technology licensing, and study different hybrid remanufacturing models.

The major difference between our study and the above research is that ours considers whether uncertified TPRs exist. The above papers assume that remanufacturing certification is mandatory for all TPRs and that there is no uncertified TPR in remanufacturing patented products. For example, Cisco and Sun, the manufacturers of IT servers, require buyers of the refurbished products to pay 
high relicensing fees for the proprietary software. "Cisco adopts a policy of non-transferability of its software to protect its intellectual property rights" (cisco.com). However, in the electrical and electronic industry, it is common to find uncertified TPRs, due to the fact that there is no software copyright issue for most e-products, such as Android phones. For instance, there are many uncertified remanufactured e-products sold on eBay. On the HP official website, there are comparisons between certified and uncertified products. "HP or an authorized HP dealer ensures that your product has been refurbished and tested to meet stringent HP standards. Brokers or third-party refurbishers may not use genuine HP components and have no adequate warranty or return policy" ( $\mathrm{hp.com}$ ). According to the market observations in the electrical and electronic industry, remanufacturing certification is a choice for both OEMs and TPRs, rather than a mandatory requirement. Therefore, our paper relaxes the assumption of mandatory certification.

Studies on certification contract selection between an OEM and a TPR are still lacking. Most studies on contract selection focus on supply chain collaboration [17-21]. Few related studies focus on technology licensing. In Hong et al. [40], the manufacturer produces both new and remanufactured products, and provides licensing to a remanufacturer. They examine two licensing patterns, fixed fee versus royalty, in a two-period closed-loop supply chain. Distinct from Hong et al.'s study [40], we examine the remanufacturing certification in the game models with three players, which contain an OEM, a certified TPR, and an uncertified TPR. In fact, the certified TPR and uncertified TPR have essential differences, which reflect the relationship with the OEM. The relationship between the certified TPR and OEM is a business cooperation, although there is still sales competition between certified remanufactured products and new products. The relationship between the uncertified TPR and OEM is one of pure competition. The competition of the uncertified TPR on the OEM and certified TPR will directly affect the contract selection. In addition, these relationships of cooperation and competition make our model unique to the electrical and electronic industry.

According to the literature review above, the extant research has not examined an OEM's remanufacturing certification contract in the secondary market of e-products with independent TPRs. Our paper attempts to fill this research gap. This study is important to e-product OEMs because, under the pressure of resource shortages, environmental protection, and legislation pressure, an increasing number of manufacturers expect to engage in recycling and reusing products in some manner [31]. The study on choosing a certification contract will directly impact the willingness to cooperate between an OEM and a TPR.

The contribution of this paper is threefold. (1) The paper studies three feasible certification contracts by building a three-player game model framework consisting of an OEM, a certified TPR, and an uncertified TPR; (2) Remanufacturing certification is a strategic choice for a TPR, and this paper studies the conditions under which an OEM and a certified TPR can achieve a win-win outcome; (3) By comparing three certification contracts, the optimal contract is discussed for the OEM, which can provide managerial insights for manufacturers' remanufacturing practice.

\section{Model Development}

As shown in Figure 1, there are two kinds of products in the e-product market, one being the new products dominated by an OEM and the other being the remanufactured ones dominated by a certified TPR (hereafter referred to as CTPR) and an uncertified TPR (referred to as UTPR). Here, our paper follows Tirole [18] and assumes that only one TPR is certified. Tirole [18] points out that at most, one downstream firm pays for a certain priority, since a second firm who also has the access will destroy the earning mode of the first downstream firm.

These two TPRs collect and remanufacture e-products and then sell them in the secondary market. A CTPR's remanufactured products have a higher market recognition compared to those of an UTPR. Our model builds a two-stage game framework for the three firms based on one period of production and sale. In the first stage, the OEM decides on the certification fee. In the second stage, the OEM and two TPRs set the prices of new and remanufactured products, respectively. Considering the huge and 
growing number of old e-products, the acquisition quantity of old products is usually much higher than that of those chosen for remanufacturing. Therefore, our paper assumes that there is no upper limit to the quantity of obtainable and reusable products.

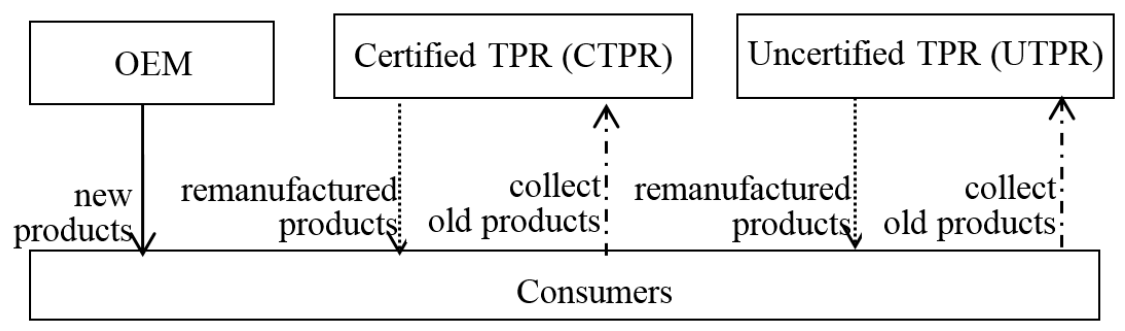

Figure 1. A market competition model for e-products.

In general, consumers' preferences vary as to whether a product is new or remanufactured, or whether a remanufacturing channel is certified by an OEM or not. We set the consumer preference for new products as 1 , and the preference for remanufactured products as against the new ones as $\alpha$. Here, $0<\alpha<1[10,39,42]$. Likewise, we assume that consumers' preference for a certified remanufacturing channel is 1 , and that their preference for a regular remanufactured channel as against the certified channel is $\beta$. Here, $0<\beta<1$ [12]. Consumers' preferences for new products, certified remanufactured products, and uncertified remanufactured products are assumed to be $1, \alpha$, and $\alpha \beta$, respectively. $\alpha$ and $\beta$ can be considered as consumers' perceived quality factors, which include attributes such as the warranty period, physical appearance, and technical specification [43]. To facilitate an understanding of the model, we provide the symbols used and their corresponding meanings in Table 1.

Table 1. Definition of symbols.

\begin{tabular}{cl}
\hline Symbol & \multicolumn{1}{c}{ Definition } \\
\hline$\alpha$ & Consumers' preference for remanufactured products as against the new ones \\
$\beta$ & Consumers' preference for regular remanufactured channel as against the certified channel \\
$c_{N}$ & Production cost for new products \\
$c_{R}$ & Production cost for remanufactured products \\
$P_{N}$ & Sales price of new products \\
$P_{A}$ & Sales price of certified remanufactured products \\
$P_{R}$ & Sales price of uncertified remanufactured products \\
$q_{N}$ & Sales volume of new products \\
$q_{A}$ & Sales volume of certified remanufactured products \\
$q_{R}$ & Sales volume of uncertified remanufactured products \\
$\pi_{N 0}$ & The manufacturer's profit in the model without CTPR \\
$\pi_{R 0}$ & UTPR's profit in the model without CTPR \\
$\pi_{N_{-} d i}$ & The manufacturer's profit in the three contracts $(i=1,2,3)$ \\
$\pi_{A} d i$ & CTPR's profit in the three contracts $(i=1,2,3)$ \\
$\pi_{R} d i$ & UTPR's profit in the three contracts $(i=1,2,3)$ \\
$h$ & Certification fee in the lump-sum payment certification contract \\
$\gamma$ & Profit-sharing percentage in the profit-sharing certification contract \\
$s$ & Unit certification fee in the piece-rate payment certification contract \\
\hline
\end{tabular}

The production costs for new and remanufactured products are $c_{N}$ and $c_{R}$, respectively. The sales prices of new products, certified remanufactured products, and uncertified remanufactured products are $P_{N}, P_{A}$, and $P_{R}$, respectively. Their corresponding sales volumes are $q_{N}, q_{A}$, and $q_{R}$, respectively.

Assume that consumers' willingness to pay is $\theta$, with a uniform distribution between $[0,1]$, which is $\theta \sim U[0,1][10,12]$. If they decide to purchase new products, the utility they get is $U_{N}=\theta-P_{N}$; if they choose to buy certified remanufactured products, the utility is $U_{A}=\alpha \theta-P_{R}$; and if they choose uncertified remanufactured products, the utility is $U_{R}=\alpha \beta \theta-P_{R}$. 
When consumers' utilities are the same between purchasing new products and certified remanufactured products, we obtain the indifference point $\theta_{1}=\left(p_{N}-p_{A}\right) /(1-\alpha)$. When consumers' utilities are the same between remanufactured products from the two TPRs, we get the indifference point $\theta_{2}=\left(p_{A}-p_{R}\right) /(\alpha-\alpha \beta)$. When the utilities are the same for consumers to buy uncertified remanufactured products and nothing, we get the indifference point $\theta_{3}=p_{R} /(\alpha \beta)$. In reality, the firm's profit has to be non-negative, otherwise they would not participate in the program. As such, we only consider the competition model in which both the OEM and the two TPRs participate, i.e., the product demands for the three sources are all nonnegative, the conditions to be met are $\theta_{1}>p_{N}, \theta_{2}>p_{A}$, and $\theta_{1}>\theta_{3}$. Figure 2 below shows the price distributions from the three sources, the indifference points, and the corresponding demands for each.

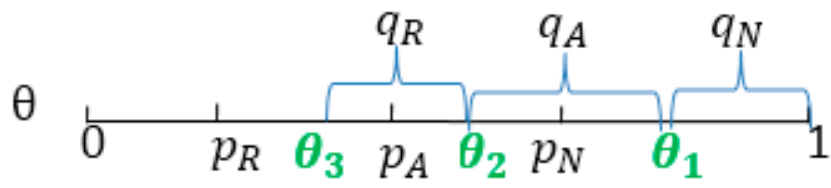

Figure 2. Price Competition in the Remanufacturing Certification Model.

Now, we can obtain the demand functions for new products, certified remanufactured products, and uncertified remanufactured products:

$$
\begin{gathered}
q_{N}=1-\left(p_{N}-p_{A}\right) /(1-\alpha), q_{A}=\left(p_{N}-p_{A}\right) /(1-\alpha)-\left(p_{A}-p_{R}\right) /(\alpha-\alpha \beta), \\
q_{R}=\left(p_{A}-p_{R}\right) /(\alpha-\alpha \beta)-p_{R} /(\alpha \beta)
\end{gathered}
$$

For the CTPR, its acceptance of remanufacturing certification must be based on the condition that its profit is higher than before. For the OEM, its acceptance of remanufacturing certification must also be based on the condition that its profit is higher than that before its approval of certification. Without a CTPR, we solve the price competition model between the OEM and UTPR. For $\theta \sim U[0,1]$, the sales quantity of new products is $1-\frac{P_{N}-P_{R}}{1-\alpha \beta}$; and that of refurbished products is $\frac{P_{N}-P_{R}}{1-\alpha \beta}-\frac{P_{R}}{\alpha \beta}$. The OEM and UTPR decide on product prices at the same time. In the model without CTPR, the OEM's profit is $\pi_{N 0}=\left(P_{N}-c_{N}\right) q_{N}$ and UTPR's profit is $\pi_{R 0}=\left(P_{R}-c_{R}\right) q_{R}$. After substituting $q_{N}$ and $q_{R}$ with $1-\frac{P_{N}-P_{R}}{1-\alpha \beta}$ and $\frac{P_{N}-P_{R}}{1-\alpha \beta}-\frac{P_{R}}{\alpha \beta}$, the profit functions are concave with respect to $P_{N}$ and $P_{R}$. By combining the first-order derivatives with respect to these two decision variables, we obtain the only equilibrium outcome. $P_{N 0}^{*}=\left(2 c_{N}+c_{R}+2-2 \alpha \beta\right) /(4-\alpha \beta)$ and $P_{R 0}^{*}=\left(2 c_{R}+\alpha \beta c_{N}+\alpha \beta(1-\alpha \beta)\right) /(4-\alpha \beta)$. Under equilibrium conditions, the OEM's profit is $\pi_{N 0}^{*}=\frac{\left(2+c_{R}-2 \alpha \beta+c_{N}(2-\alpha \beta)\right)^{2}}{(4-\alpha \beta)^{2}(1-\alpha \beta)}$.

Next, we establish the game models to analyze the lump-sum payment contract, the profit-sharing payment contract, and the piece-rate payment contract. To conveniently distinguish them, we use the subscript " $i$ " $(i=1,2,3)$ to label the variables shown in the three contracts.

\section{Lump-Sum Payment Contract}

In the lump-sum payment certification contract, CTPR will only pay the OEM once at the very beginning, irrespective of its remanufacturing quantity. After being certified, CTPR will benefit from the manufacturer's brand to enhance consumers' preference for its remanufactured products.

In the first stage of the game, the OEM sets its certification fee $h$. In the second stage, the OEM decides on the sale prices of its new products $P_{N}$, and the CTPR and UTPR decide on the prices of their remanufactured products $P_{A}$ and $P_{R}$, respectively. We proceed backwards, to derive the equilibrium of this Stackelberg game. Given a certification fee, we first examine the price competition among the three firms and obtain the equilibrium solutions. Then, we discuss the optimal certification fee and explore the conditions for a win-win outcome. 
The profit functions of the manufacturer, CTPR, and UTPR are:

$$
\begin{gathered}
\pi_{N_{-} d 1}=\left(p_{N}-c_{N}\right) q_{N}+h \\
\pi_{A_{\_} d 1}=\left(p_{A}-c_{R}\right) q_{A}-h \\
\pi_{R \_d 1}=\left(p_{R}-c_{R}\right) q_{R}
\end{gathered}
$$

After substituting the demand with Formula (1), the profit functions are concave with respect to $p_{N}, p_{A}$, and $p_{R}$. Combining the first-order derivatives with respect to these three decision variables, we obtain the only equilibrium outcome as follows.

Proposition 1. In the model of a lump-sum payment contract, the equilibrium prices and corresponding sales quantities can be summarized as follows:

$$
\begin{gathered}
P_{N_{-} d 1}^{*}=\frac{c_{R}(3-\alpha-2 \alpha \beta)+c_{N}(4-\beta-3 \alpha \beta)+(1-\alpha)(4-\beta-3 \alpha \beta)}{2(4-\alpha-\beta-2 \alpha \beta)} \\
P_{A_{-} d 1}^{*}=\frac{\left(1+c_{N}-\alpha\right) \alpha(1-\beta)+c_{R}(3-\alpha-2 \alpha \beta)}{4-\alpha-\beta-2 \alpha \beta} \\
P_{R_{-} d 1}^{*}=\frac{\left(1+c_{N}-\alpha\right) \alpha(1-\beta) \beta+c_{R}\left(4-\alpha+2 \beta-3 \alpha \beta-2 \alpha \beta^{2}\right)}{2(4-\alpha-\beta-2 \alpha \beta)} \\
q_{N_{-} d 1}^{*}=\frac{c_{R}(3-\alpha-2 \alpha \beta)+(-1+\alpha)(-4+\beta+3 \alpha \beta)+c_{N}(-4+\beta+\alpha(2+\beta))}{2(-1+\alpha)(-4+\alpha+\beta+2 \alpha \beta)} \\
q_{A_{-} d 1}^{*}=\frac{\left(c_{R}+\alpha\left(-1-c_{N}+\alpha\right)\right)(-1+\alpha \beta)}{(-1+\alpha) \alpha(-4+\alpha+\beta+2 \alpha \beta)} \\
q_{R_{-} d 1}^{*}=\frac{\alpha\left(-1-c_{N}+\alpha\right) \beta-c_{R}(-4+\alpha+2 \alpha \beta)}{2 \alpha \beta(-4+\alpha+\beta+2 \alpha \beta)}
\end{gathered}
$$

To ensure that the demands are nonnegative, there are three constraints in the form of inequalities:

$$
\begin{gathered}
P_{N_{-} d 1}^{*}-P_{A_{-} d 1}^{*} / \alpha>0 \\
P_{A_{-} d 1}^{*} / \alpha-P_{R_{-} d 1}^{*} /(\alpha \beta)>0
\end{gathered}
$$

and:

$$
\left(P_{N \_d 1}^{*}-P_{A \_d 1}^{*}\right) /(1-\alpha)-\left(P_{N \_d 1}^{*}-P_{R \_d 1}^{*}\right) /(1-\alpha \beta)>0
$$

After further examination and analysis, we can simplify the three constraints into one: $c_{R}<\alpha\left(1+c_{N}-\alpha\right) \beta /(4-\alpha-2 \alpha \beta)$. Based on the above equilibrium decisions, the static analysis with respect to $\alpha$ and $\beta$ can be obtained in Corollary 1 below.

\section{Corollary 1.}

(1) $P_{N_{-} d 1}^{*}$ is positively correlated with $\beta$, and $q_{N_{-} d 1}^{*}$ is negatively correlated with $\beta$. If $\alpha$ and $\beta$ are high enough, which means that $\alpha$ approximates 1 and $\beta$ is beyond $\left(12-4 c_{N}\right) /\left(12-c_{N}\right)$, then $P_{N \_d 1}^{*}$ is positively correlated with $\alpha$; otherwise it is negatively correlated with $\alpha . q_{N_{-} d 1}^{*}$ is positively correlated with $\alpha$ if $\alpha, \beta$, and $c_{N}$ all have sufficiently low values.

According to the above results, if consumers' preference for remanufactured products $\alpha$ is very high and UTPR has a high degree of market recognition, then a rise in a will lead to an increase in the price of new products; otherwise, it will cause a decrease. 
(2) $\quad P_{A_{-} d 1}^{*}$ and $\beta$ are negatively correlated, and $q_{A_{-} d 1}^{*}$ and $\beta$ are positively correlated.

When consumers' preference for the uncertified remanufacturing channel $\beta$ goes up, in response to UTPR's competition, CTPR will lower the price of remanufactured products to increase the sales volume.

(3) There exists a $\beta^{*}$, so that when $\beta>\beta^{*}, P_{R_{-} d 1}^{*}$ and $\beta$ are negatively correlated; when $\beta<\beta^{*}, P_{R_{-} d 1}^{*}$ and $\beta$ are positively correlated. $q_{R_{-}}^{*} d 1$ and $\beta$ are positively correlated.

When consumers' preference for the uncertified remanufacturing channel $\beta$ goes up, UTPR's competitiveness improves, its sales volume will increase, but the change direction of the sales price is uncertain. As $\beta$ increases gradually in the range of $[0,1]$, the sales price will first go up, and then go down.

According to Corollary 1, as consumers' preference for the regular remanufactured channel over the certified channel grows, which indicates increasing competitiveness for the UTPR, the OEM will reduce the price of new products to obtain a bigger market share, as will the CTPR. However, the UTPR will raise the price of its products if consumers' preference for the regular remanufactured channel is quite low, in order to enlarge its profit margin. Only if consumers' preference for the regular remanufactured channel has been sufficiently high, will the UTPR adopt the strategy of price reduction because of the competitive pressure from the OEM and CTPR.

As consumers' preference for remanufactured products over the new ones increases, the OEM will not necessarily adopt the strategy of reducing prices. If the remanufactured products have great market recognition, and the certified products do not have an obvious competitive advantage compared with uncertified ones, then the OEM will raise the price of new products. As such, under a remanufacturing certification contract, the influence of consumers' preference for remanufactured products on the OEM's pricing of new products is related to TPRs' competitiveness. This is because the OEM has to consider all relevant factors, including the CTPR's profitability, when it comes to optimizing its total profit.

Corollary 2. The condition for the CTPR to choose certification is $\pi_{A_{\_} d 1}^{*} \geq 0$. When the certification fee exceeds a certain amount, the CTPR will choose not to be certified. Therefore, we get the following:

$$
h \leq h_{\text {Max }}=\frac{-\left(c_{R}{ }^{2}(-1+\beta)(-1+\alpha \beta)-2 c_{R}\left(1+c_{N}-\alpha\right) \alpha(-1+\beta)(-1+\alpha \beta)+\alpha\left(\left(1+c_{N}-\alpha\right)^{2} \alpha(-1+\beta)(-1+\alpha \beta)\right)\right)}{(-1+\alpha) \alpha(-4+\alpha+\beta+2 \alpha \beta)^{2}} .
$$

Remark 1. If $c_{N}$ and $\alpha$ are high enough, and $\beta$ is small enough, then $\pi_{N_{-} d 1}^{*}-\pi_{N 0}^{*}>0$ at the point of $h=h_{\text {Max }}$. As such, the OEM and CTPR have a win-win outcome through certification.

The reasons are as follows. When $h=h_{M a x}, \pi_{N \_d 1}^{*}-\pi_{N 0}^{*}$ is positively correlated with $c_{N}$. As $\beta$ increases, $\pi_{N \_d 1}^{*}-\pi_{N 0}^{*}$ will first go up, and then go down. As $\alpha$ increases, $\pi_{N \_d 1}^{*}-\pi_{N 0}^{*}$ will first go down, and then go up. Therefore, there exist thresholds $\overline{c_{N}}, \bar{\alpha}$, and $\bar{\beta}$, such that when $c_{N}>\overline{c_{N}}$, $\alpha>\bar{\alpha}$, and $\beta<\bar{\beta}$, we have $\pi_{N_{-} d 1}^{*}-\pi_{N 0}^{*}>0$.

According to Remark 1 above, when the cost of new products is relatively high, consumers' preference for remanufactured products is sufficiently high, and the difference in consumers' preferences between the two remanufacturing channels is significant, indicating that the remanufactured products have a promising prospect, especially for certified remanufactured products, then the OEM would be willing to certify a TPR, resulting in a win-win outcome.

\section{Profit-Sharing Payment Contract}

The profit-sharing certification contract is based on the predetermined economic sharing rule, which defines the split of gains between two contract participants. It is a cooperation contract that enables the OEM and CTPR to share the benefit of the OEM's brand value. 
In the first stage of the game, the OEM sets a profit-sharing percentage $\gamma$. In the second stage, the OEM and TPRs decide on their respective sale prices. Similar to the lump-sum contract, the backward induction method is used to solve this Stackelberg game. Given the percentage $\gamma$, we first examine the price competition among the three firms. Then, we discuss the OEM's and the CTPR's optimal profit-sharing percentage and explore the conditions for a win-win outcome.

The profit functions of the OEM, CTPR, and UTPR are:

$$
\begin{gathered}
\pi_{N \_d 2}=\left(p_{N}-c_{N}\right) q_{N}+\gamma\left(p_{A}-c_{R}\right) q_{A} \\
\pi_{A_{\_} d 2}=(1-\gamma)\left(p_{A}-c_{R}\right) q_{A} \\
\pi_{R \_d 2}=\left(p_{R}-c_{R}\right) q_{R}
\end{gathered}
$$

Proposition 2. In the model of a profit-sharing payment contract, the equilibrium prices can be summarized as follows:

$$
\begin{gathered}
P_{N_{-} d 2}^{*}=\frac{c_{N}(4-\beta-3 \alpha \beta)+(1-\alpha)(4-\beta-3 \alpha \beta)+c_{R}(3-\alpha(1+\beta(2-\gamma)+\gamma)-(1-\beta) \gamma)}{8-2 \beta+2 \alpha(-1+\beta(-2+\gamma)-\gamma)} \\
P_{A_{-} d 2}^{*}=\frac{\left(1+c_{N}-\alpha\right) \alpha(1-\beta)+c_{R}(3+\alpha(-1+\beta(-2+\gamma)-\gamma))}{4-\beta+\alpha(-1+\beta(-2+\gamma)-\gamma)} \\
P_{R_{-} d 2}^{*}=\frac{\left(1+c_{N}-\alpha\right) \alpha(1-\beta) \beta+c_{R}(2(2+\beta)-\alpha(1+\beta)(1+\beta(2-\gamma)+\gamma))}{8-2 \beta+2 \alpha(-1+\beta(-2+\gamma)-\gamma)}
\end{gathered}
$$

To ensure that the demands are nonnegative, we have three constraints in the form of inequalities:

$$
\begin{gathered}
P_{N_{\_} d 2}^{*}-P_{A_{-} d 2}^{*} / \alpha>0 \\
P_{A_{-} d 2}^{*} / \alpha-P_{R_{-} d 2}^{*} /(\alpha \beta)>0
\end{gathered}
$$

and:

$$
\left(P_{N \_d 2}^{*}-P_{A \_d 2}^{*}\right) /(1-\alpha)-\left(P_{N \_d 2}^{*}-P_{R \_d 2}^{*}\right) /(1-\alpha \beta)>0
$$

After further examination and analysis, we can simplify the three constraints to one: $c_{R}<\alpha\left(1+c_{N}-\alpha\right) \beta /(4-\alpha(1+\beta(2-\gamma)+\gamma))$. Based on the above equilibrium decisions, the static analysis with respect to $\gamma$ and $\beta$ can be obtained in Corollary 3 below.

\section{Corollary 3.}

(1) The influences of the profit-sharing percentage $\gamma$ on prices are: $\frac{\partial P_{N-d 2}^{*}}{\partial \gamma}>0 ; \frac{\partial P_{A-d}^{*}}{\partial \gamma}>0 ; \frac{\partial P_{R_{d} d 2}^{*}}{\partial \gamma}>0$. The influence of consumers' preferences $\beta$ on prices are: $\frac{\partial P_{N}^{*} \frac{1}{\partial \beta}}{\partial \bar{\beta}}<0 ; \frac{\partial P_{A-d}^{*}}{\partial \bar{\beta}}<0$; when $\beta<\beta^{*}, \frac{\partial P_{R_{d}}^{*} \bar{\beta}}{\partial \bar{\beta}}>0$; when $\beta>\beta^{*}, \frac{\partial P_{R}^{*} d 2}{\partial \bar{\beta}}<0$

Here:

$$
\begin{aligned}
\beta^{*} & =4 \alpha\left(1+c_{N}-c_{R}(-2+\gamma)\right)+\alpha^{3}(1+\gamma)-\frac{\alpha^{2}\left(5+\gamma+c_{N}(1+\gamma)+c_{R}\left(2+\gamma-\gamma^{2}\right)\right)}{\alpha\left(-1-c_{N}+\alpha+c_{R}(2-\gamma)\right)(1+\alpha(2-\gamma))} \\
& -\sqrt{3} \sqrt{(-1+\alpha) \alpha\left(c_{R}+\alpha(-1-c n+\alpha)\right)\left(-1-c_{N}+\alpha+c_{R}(-2+\gamma)\right)(-4+\alpha+\alpha \gamma)} .
\end{aligned}
$$

If $\gamma$ increases, then the prices of new and remanufactured products will all go up. As $\beta$ increases, the prices of new and certified remanufactured products will decrease, and the price of uncertified remanufactured products could go up or down, depending on the value of $\beta$. If $\beta$ is high enough, then the price of the UTPR's remanufactured products is negatively correlated with $\beta$; otherwise, it is positively correlated. 
(2) The influences of the profit-sharing percentage $\gamma$ on sale volumes are: $\frac{\partial q_{N, d 2}^{*}}{\partial \gamma}<0 ; \frac{\partial q_{A d 2}^{*}}{\partial \gamma}>0 ; \frac{\partial q_{R d 2}^{*}}{\partial \gamma}>0$. The influence of consumers' preference for the uncertified channel on sales volumes are: $\frac{\partial q_{N-d}^{*}}{\partial \bar{\beta}}<0$; $\frac{\partial q_{R}^{*} d 2}{\partial \bar{\beta}}>0 ;$ when $\gamma>(1-\alpha) / \alpha, \frac{\partial q_{A-d 2}^{*}}{\partial \bar{\beta}}<0$; when $\gamma<(1-\alpha) / \alpha, \frac{\partial q_{A-d}^{*}}{\partial \bar{\beta}}>0$.

According to the above results, if $\gamma$ increases, the prices of all the products will go up, but the sales volume of new products will go down and that of the remanufactured products will go up. As $\beta$ increases, the sales volume of new products goes down and that of the UTPR goes up. As $\beta$ increases, although the prices of the CTPR's products are going down, its sales volume may go up or down, depending on the value of $\gamma$.

(3) The influences of the profit-sharing percentage $\gamma$ on firms' profits are: $\frac{\partial \pi_{N-d 2}^{*}}{\partial \gamma}>0 ; \frac{\partial \pi_{A-d}^{*}}{\partial \gamma}<0 ; \frac{\partial \pi_{R, d 2}^{*}}{\partial \gamma}>0$. An increase in $\gamma$ can boost the profits of the OEM and UTPR, but lower the profit of the CTPR.

According to Corollary 3, when consumers' preference for the regular remanufactured channel over the certified channel grows, which means that the difference in consumers' preferences between the two remanufacturing channels is narrowing, both the OEM and CTPR will reduce their prices. However, distinct from the results under the lump-sum payment contract, the CTPR's sales volume does not necessarily increase under the profit-sharing payment contract. If the percentage of profit sharing is sufficiently high, its sales volume will go down, which represents the impact of certification payment on the CTPR's remanufacturing activity.

As the profit-sharing percentage increases, the OEM and TPRs will all adopt the strategy of raising prices. The OEM will give up some proportion of the market share of new products and expect a growing market share of the CTPR's remanufactured products. As such, the final outcome will be a higher profit for the OEM and lower profit for the CTPR. Therefore, when the profit-sharing percentage exceeds a certain value, the CTPR will choose not to be certified. According to our assumption on a CTPR's participation constraints, the condition for CTPR to accept certification is $\pi_{A_{-} d 2}^{*} \geq 0$, which means $\gamma \leq 1$.

Remark 2. When $c_{N}$ is big enough, then $\pi_{N_{-} d 2}^{*}-\pi_{N 0}^{*}>0$ at the point of $\gamma=1$. As such, the OEM and CTPR have a win-win outcome through certification.

When $\gamma=1$, the profit difference $\pi_{N d 2}^{*}-\pi_{N 0}^{*}$ is positively correlated with $c_{N}$. Only when $c_{N}$ is high enough, will the profit difference be positive. When the production cost of new products is sufficiently high, the OEM can make a profit from the certification, and the profit of the CTPR will also go up. The OEM and CTPR can negotiate their profit-sharing percentage so that they can have a win-win outcome. Here, the higher the consumers' preference for remanufactured products $(\alpha)$, the greater the increase in their profits. However, when the production cost of new products is relatively low, the OEM's new products will be much more competitive than the remanufactured products. As such, the benefits that remanufacturing certification bring to the OEM are not so tempting, and may not offset the competition that certified remanufactured products provide to the new products. Therefore, the OEM is unwilling to adopt certification in this case.

\section{Piece-Rate Payment Contract}

In the piece-rate payment certification contract, the certification fees are based on the number of products remanufactured. The total fee that the CTPR pays will depend on both the unit certification fee and the number of remanufactured products. Once a piece of product is remanufactured, a unit certification fee will be charged to the CTPR.

In the game framework, the OEM needs to set a unit certification fee $s$, and then the three parties decide on the sale prices of their products. Similar to the lump-sum contract, the backward induction method is used to solve this Stackelberg game. Given the unit certification fee $s$, we first examine the 
price competition among the three firms. Then, we discuss the OEM's and CTPR's optimal certification fee and explore the conditions for a win-win outcome.

The profit functions of the manufacturer, CTPR, and UTPR, respectively, are:

$$
\begin{gathered}
\pi_{N \_d 3}=\left(p_{N}-c_{N}\right) q_{N}+s q_{A} \\
\pi_{A \_d 3}=\left(p_{A}-c_{R}-s\right) q_{A} \\
\pi_{R \_d 3}=\left(p_{R}-c_{R}\right) q_{R}
\end{gathered}
$$

Proposition 3. In the model of a piece-rate payment contract, the equilibrium prices can be summarized as follows:

$$
\begin{gathered}
P_{N_{-} d 3}^{*}=\frac{4+6 s-4 \alpha-\beta-s \beta-2 \alpha \beta-5 s \alpha \beta+3 \alpha^{2} \beta-c_{R}(3-\alpha-2 \alpha \beta)+c_{N}(4-\beta-3 \alpha \beta)}{2(4-\alpha-\beta-2 \alpha \beta)} \\
P_{A_{-} d 3}^{*}=\frac{\left(1+c_{N}-\alpha\right) \alpha(1-\beta)+c_{R}(3-\alpha-2 \alpha \beta)+s(2+\alpha-3 \alpha \beta)}{4-\alpha-\beta-2 \alpha \beta} \\
P_{R_{-} d 3}^{*}=\frac{c_{R}\left(4-\alpha+2 \beta-3 \alpha \beta-2 \alpha \beta^{2}\right)+\beta\left(\left(1+c_{N}-\alpha\right) \alpha(1-\beta)+s(2+\alpha-3 \alpha \beta)\right)}{2(4-\alpha-\beta-2 \alpha \beta)}
\end{gathered}
$$

To ensure that the demands are nonnegative; we have three constraints in the form of inequalities:

$$
\begin{gathered}
P_{N_{\_} d 3}^{*}-P_{A_{-} d 3}^{*} / \alpha>0 \\
P_{A_{-} d 3}^{*} / \alpha-P_{R_{-} d 3}^{*} /(\alpha \beta)>0
\end{gathered}
$$

and:

$$
\left(P_{N \_d 3}^{*}-P_{A \_d 3}^{*}\right) /(1-\alpha)-\left(P_{N \_d 3}^{*}-P_{R \_d 3}^{*}\right) /(1-\alpha \beta)>0
$$

Further analysis and discussion helps to simplify them to:

$$
\left(-c_{R}(1-\beta)(4-\alpha-2 \alpha \beta)+\beta\left(\left(1+c_{N}-\alpha\right) \alpha(1-\beta)+s(2+\alpha-3 \alpha \beta)\right)\right)>0
$$

and:

$$
\left(s(1-\alpha)(-2+\beta)+c_{R}(-1+\beta)-\left(1+c_{N}-\alpha\right) \alpha(-1+\beta)\right)>0
$$

Based on the above equilibrium decisions, the static analysis with respect to $s$ and $\beta$ can be obtained in Corollary 4 below.

\section{Corollary 4.}

(1) The impacts of the certification fee son prices are: $\frac{\partial P_{N d 3}^{*}}{\partial s}>0 ; \frac{\partial P_{A d}^{*} d 3}{\partial s}>0 ; \frac{\partial P_{R, d 3}^{*}}{\partial s}>0$. Prices are influenced by consumers' preference $\beta$ in the uncertified channel: $\frac{\partial P_{N}^{*} d 3}{\partial \beta}<0, \frac{\partial P_{A-d 3}^{*}}{\partial \beta}<0$. Only when $\beta$ is extremely high, $\frac{\partial P_{R_{d} d 3}^{*}}{\partial \beta}<0$; or else, $\frac{\partial P_{R_{-} d 3}^{*}}{\partial \beta}>0$.

According to Corollary 4 (1), when the certification fee increases, the prices of both new products and remanufactured products will go up. As $\beta$ increases, indicating that the difference in consumers' preferences between the two channels is narrowing, the prices of new and certified remanufactured products will go down. As $\beta$ increases, the price of uncertified remanufactured products will also go up, until $\beta$ becomes extremely high, because the falling prices of the other two products compel the UTPR to lower its prices. 
(2) The influences of the certification fee s on sales volumes are: $\frac{\partial q_{N d}^{*} d 3}{\partial s}<0 ; \frac{\partial q_{A d 3}^{*}}{\partial s}<0 ; \frac{\partial q_{R d 3}^{*}}{\partial s}>0$. The influence of consumers' preference $\beta$ in the uncertified channel on sales volumes are: $\frac{\partial q_{N-d}^{*} d 3}{\partial \bar{\beta}}<0$; $\frac{\partial q_{A}^{*} d 3}{\partial \beta}<0 ; \frac{\partial q_{R, d 3}^{*}}{\partial \beta}>0$.

As the certification fee increases, all prices will go up, but the sales volumes of new and certified remanufactured products will go down, while that of uncertified remanufactured products will go up. As the consumers' preference $\beta$ increases, the sales volume of new products and certified remanufactured products will go down, while that of uncertified remanufactured products will go up. Therefore, the increase in s and $\beta$ is beneficial for the UTPR.

(3) The influences of the certification fee s on the firms' profits are: $\frac{\partial \pi_{A \_d 3}^{*}}{\partial s}<0$; $\frac{\partial \pi_{R_{d} d 3}^{*}}{\partial s}>0$. When $s<s^{*}$, $\frac{\partial \pi_{N d d 3}^{*}}{\partial s}>0 ;$ when $s>s^{*}, \frac{\partial \pi_{N}^{*} d 3}{\partial s}<0$. The condition for the CTPR to accept certification is: $\pi_{A_{-} d 3}^{*} \geq 0$, which requires $s<s^{\prime}$ to hold. When the certification fee exceeds $s^{\prime}$, the CTPR will choose not to be certified.

Here:

$$
\begin{gathered}
s^{*}=\left(c_{R}(-1+\beta)\left(8-2 \beta+2 \alpha(-7+\beta) \beta+\alpha^{2}\left(-1+\beta+6 \beta^{2}\right)\right)-\alpha(-1+\beta)(-4(-4+\beta)+\right. \\
\left.\left.\alpha^{2} \beta(-1+13 \beta)+\alpha\left(2-31 \beta+5 \beta^{2}-c_{N}\left(2-3 \beta+\beta^{2}\right)\right)\right)\right) /((2-\beta)(-4(-4+\beta)+ \\
\left.\left.\alpha^{2} \beta(-1+13 \beta)+\alpha\left(2-31 \beta+5 \beta^{2}\right)\right)\right), \\
s^{\prime}=\left(\left(1+c_{N}-\alpha\right) \alpha(1-\beta)+c_{R} \beta-c_{R}\right) /((-1+\alpha)(-2+\beta)) .
\end{gathered}
$$

According to Corollary 4, the UTPR benefits from an increasing certification fee because its sales price and volume will both go up, leading to a higher profit. In contrast to the UTPR, the CTPR gets hurt from an increasing certification fee. Due to the expenditure on the certification payment, the CTPR will have to raise the price of its remanufactured products, which lowers the sales volume and decreases its profit. It appears that the OEM would always benefit from a higher certification fee. However, this is not always the case. An excessive certification fee may lower the OEM's profit.

Distinct from the results under the lump-sum and profit-sharing payment contracts, when consumers' preference for the regular remanufactured channel over the certified channel increases, the sales volume of new products and the CTPR's remanufactured products will keep decreasing, although they have adopted the price reduction strategy. This is because, under the piece-rate payment contract, the sale of certified remanufactured products is a big concern for the CTPR and cannot be kept very high, especially if the UTPR is more competitive.

We continue to analyze the optimal certification fee for both the OEM and CTPR. The results are shown in the following Corollary 5.

Corollary $5 . s^{*}-s^{\prime}$ is positively correlated with $c_{R}$, but negatively correlated with $c_{N}$. When $c_{N}$ is big enough and $c_{R}<\frac{2 c_{N} \alpha}{1+\alpha}$, we have $s^{*}<s^{\prime}$ and the OEM will choose $s^{*}$ as its optimal certification fee. The CTPR's profit is higher than that before being certified. There exists a $\hat{c_{R}}$, such that if $c_{R}<\hat{c_{R}}$, then $\pi_{N_{-} d 3}^{*}-\pi_{N 0}^{*}>0$, indicating that both the OEM and CTPR will benefit from the certification.

According to Corollary 5, the OEM will not necessarily choose a very high certification fee. Instead, the OEM will consider the competitiveness of certified remanufactured products and new products, and then choose an appropriate certification fee, which maximizes its total profits from new production and remanufacturing certification.

Remark 3. When the production cost of new products $c_{N}$ is small enough and that of remanufactured products $c_{R}>\frac{2 c_{N} \alpha}{1+\alpha}$, we have $s^{*}>s^{\prime}$, and the OEM will choose $s^{\prime}$ as its optimal certification fee. When $s=s^{\prime}$, we find that $\pi_{N \_d 3}^{*}-\pi_{N 0}^{*}<0$, and the certification contract will not be adopted. 
Remark 4. If the production cost of new products $c_{N}$ is high enough and that of remanufactured products $c_{R}$ is sufficiently low, then $s^{*}<s^{\prime}$, indicating that the OEM's most desirable certification fee will be lower than the maximum certification fee that the CTPR can accept. When $s=s^{*}$, we find that $\pi_{N_{-} d 3}^{*}-\pi_{N 0}^{*}>0$. As such, the OEM and CTPR have a win-win outcome through certification.

According to the above results, when the competitiveness of new products is weak and the remanufacturer has a cost advantage, the OEM will choose a certification fee that benefits the CTPR. Therefore, a piece-rate payment contract will be adopted. However, when the competitiveness of new products is strong, and the remanufacturing does not have a cost advantage, an agreement on the piece-rate payment contract will not be reached.

\section{Comparison of the Three Contracts}

After analyzing the certification contracts, we now provide the conditions under which the OEM will adopt each of them. Limited by the calculation complexity of the problem (three players in a two-stage game with nonnegative-demand constraints), we follow Oraiopoulos et al.'s approach [10] and use a numerical simulation with all possible parameter combinations to make the profit comparison.

Remark 5. If TPRs' profit margin is strong ( $\alpha$ is very big, and $c_{R}$ is small enough), and the difference in consumers' preference between the certified and uncertified channels is small ( $\beta$ is big enough), then the OEM's profit will be highest under the profit-sharing payment contract; otherwise, the piece-rate payment contract will be optimal for the manufacturer.

The conclusions in Remark 5 can be explained by examining the case where remanufactured products have very strong competitiveness, i.e., they have a high degree of market recognition and low remanufacturing costs. The results are summarized below:

(1) If the difference in consumers' preference between the certified and uncertified channels is significant enough, then the piece-rate payment contract is the best option for the OEM to adopt. This is because the CTPR has a competitive advantage in the market and its sales quantity is large, which will provide a considerable certification fee for the OEM in the piece-rate contract.

(2) If the difference in consumers' preferences between the certified and uncertified channels is sufficiently small, the OEM obtains the highest profit when using the profit-sharing payment contract. This is because the CTPR's competitive advantage is weak when compared with the UTPR, and the number of remanufactured products will be relatively small. As such, the piece-rate contract is inappropriate for the manufacturer. However, since remanufactured products have the advantage of low costs and are still very popular in the market, TPRs can make a good profit. Therefore, it is best for the OEM to choose the profit-sharing payment contract, which will provide a considerable certification payment.

In the case where remanufactured products do not have a strong competitive position, the OEM prefers the piece-rate payment contract, even if the difference in consumers' preferences between the certified and uncertified channels is small and the CTPR's remanufacturing volume is low. This is because, when the CTPR has a weak profitability, the OEM is not willing to be involved in the CTPR's profit. As such, the profit-sharing payment contract is not a good choice for the OEM.

We provide an example of numerical simulation in Figure 3 to graphically show the results. Here, we assume that $c_{N}=0.35$. In Figure 3, the left graph is the case where $\alpha=0.6$ and $c_{R}=0.1$, and the right graph is the case where $\alpha=0.8$ and $c_{R}=0.05$. The horizontal axis is $\beta$, representing the consumers' preference for the regular remanufactured channel as against the certified channel. The vertical axis represents the OEM's profit in different contracts. Among the three curves, the regular one is the OEM's profit in the lump-sum payment contract, the dashed one is that in the profit-sharing 
payment contract, and the bold one is that in the piece-rate payment contract. In the case where $\alpha=0.6$ and $c_{R}=0.1$, the piece-rate payment contract is dominant. In the case where $\alpha=0.8$ and $c_{R}=0.05$, if $\beta$ ( $>0.35$ ) is high, then the profit-sharing payment contract is optimal; otherwise, the piece-rate payment contract is optimal.

According to the above results, the lump-sum payment contract is generally not favored. Only when the profitability of remanufactured products is good, can the OEM and CTPR reach an agreement on the certification contract. However, if they decide on an agreement, the OEM will obtain a higher profit with the other two contracts (profit-sharing and piece-rate). When the profitability of remanufactured products is weak, the OEM may have its highest profits in the lump-sum payment contract, but the OEM and CTPR will not be able to reach a certification agreement.

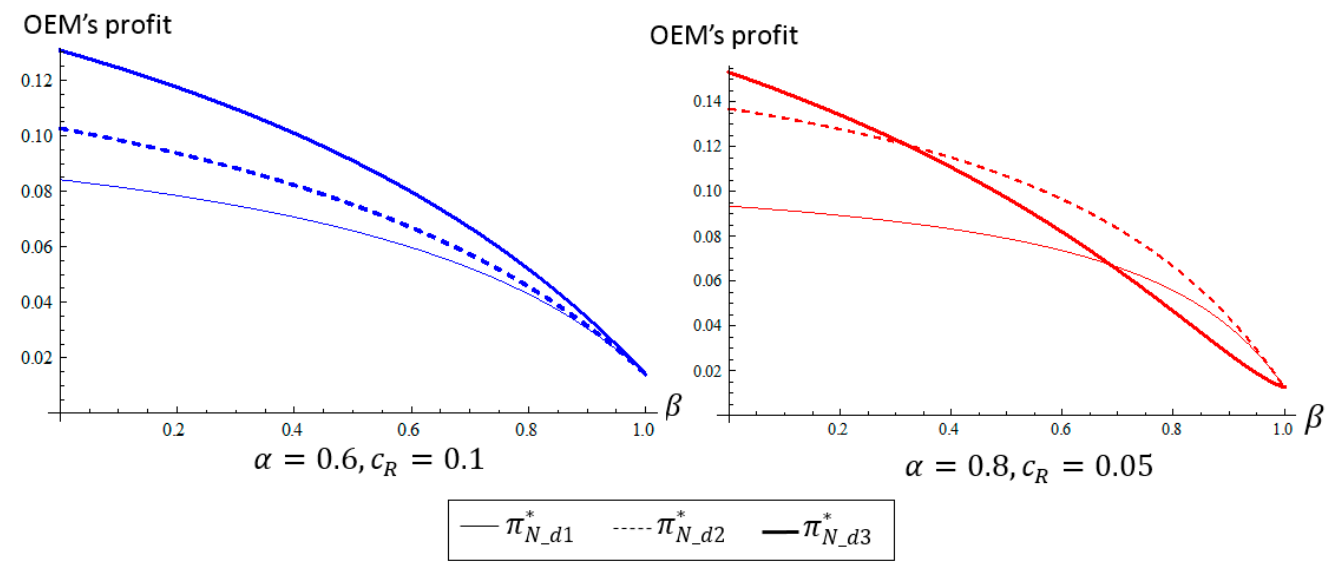

Figure 3. Comparison of the OEM's profits under different parameter combinations.

In summary, the application conditions for the three payment contracts are organized in Table 2.

Table 2. The applicable conditions of contract types.

\begin{tabular}{|c|c|c|}
\hline Contract Type & Description & Applicable Conditions \\
\hline $\begin{array}{l}\text { Lump-sum } \\
\text { payment contract }\end{array}$ & $\begin{array}{l}\text { CTPR pays a one-time } \\
\text { certification fee to } \\
\text { the OEM }\end{array}$ & $\begin{array}{l}\text { Not chosen compared with profit-sharing or } \\
\text { piece-rate payment contracts. }\end{array}$ \\
\hline $\begin{array}{l}\text { Profit-sharing } \\
\text { payment contract }\end{array}$ & $\begin{array}{l}\text { CTPR pays a certain } \\
\text { percentage of its profit to } \\
\text { the OEM }\end{array}$ & $\begin{array}{l}\text { - If remanufactured products have a high } \\
\text { degree of market recognition and low } \\
\text { remanufacturing costs, and the difference in } \\
\text { consumers' preferences between the certified } \\
\text { and uncertified channels is sufficiently small, } \\
\text { then the OEM gets the highest profit in the } \\
\text { profit-sharing payment contract. }\end{array}$ \\
\hline $\begin{array}{l}\text { Piece-rate } \\
\text { payment contract }\end{array}$ & $\begin{array}{l}\text { CTPR pays a certification } \\
\text { fee for each } \\
\text { remanufactured product }\end{array}$ & $\begin{array}{l}\text { - If remanufactured products have a high } \\
\text { degree of market recognition and low } \\
\text { remanufacturing costs, and the difference in } \\
\text { consumers' preference between the certified } \\
\text { and uncertified channels is significant enough, } \\
\text { then the piece-rate payment contract is the } \\
\text { best option for the OEM to adopt. } \\
\text { If remanufactured products do not have a } \\
\text { strong competitive position, i.e., with a low } \\
\text { degree of market recognition and high } \\
\text { remanufacturing costs, the OEM prefers the } \\
\text { piece-rate payment contract. }\end{array}$ \\
\hline
\end{tabular}




\section{Conclusions}

In the electrical and electronic market, there are OEM new products, as well as TPR remanufactured products which exert competitive pressures on new products. In general, consumers have a higher preference for manufacturer-certified remanufactured products than regular ones. Based on this observation, remanufacturing certification is a strategy that OEMs can use to benefit from product remanufacturing. As a form of engaging in remanufacturing, certifying a qualified TPR to remanufacture has been adopted by some OEMs. Our paper studies three contracts that explain how a certification payment will be charged to TPRs, which include the lump-sum payment contract, profit-sharing payment contract, and piece-rate payment contract.

In the lump-sum payment contract, as the difference in consumers' preferences between certified and uncertified remanufacturing channels narrows, both the OEM and the certified TPR will lower their prices in response to the competition from the uncertified TPR. Therefore, an excessively small difference in consumers' preferences between the two channels may not yield a good performance for the uncertified TPR, because a strong response from both the OEM and the certified TPR will be triggered. By comparing the equilibrium profits before and after certification, results show that if the cost of new products is high enough, consumers' preference for remanufactured products is sufficiently big, and the difference in consumer preferences between the two channels is significant, then the OEM is willing to certify a TPR, resulting in a win-win outcome.

In the profit-sharing payment contract, when the production costs of new products are sufficiently high, the OEM makes a profit from the remanufacturing certification. The OEM and certified TPR can negotiate the profit-sharing percentage to achieve a win-win outcome. As the consumers' preference for remanufactured products becomes stronger, the growth in profits of the two sides will increase. However, when the production cost of new products is relatively low, the OEM's new products will be much more competitive than the remanufactured products. Therefore, the benefits that remanufacturing certification brings to the OEM may not offset the competition that certified remanufactured products provide to the new products. Therefore, the OEM is unwilling to adopt certification.

In the piece-rate payment contract, if the production costs of remanufactured products are low enough and those of the new products are high enough, then the OEM's most desirable certification fee will be lower than the highest acceptable fee that the certified TPR will accept. In this case, the profits of both the OEM and certified TPR will be superior to those before certification. As such, both sides will benefit from this contract. However, if the OEM's desirable certification fee is greater than the TPR's acceptance bottom-line, the certified TPR will suffer a loss and a certification agreement will not be reached.

If the TPRs' profit margin is strong and there is no large difference in consumers' preferences between the certified and the uncertified remanufacturing channels, then the profit-sharing payment contract provides the OEM with the highest profit; otherwise, the piece-rate payment contract is the best option.

Our research conclusions provide managerial insights for OEMs who might have doubts about the benefits of implementing remanufacturing certification. We have provided the basis for future research into this interesting research area, including an investigation of other forms of certification contracts. In addition, we could expand the model to include multiple certified TPRs, as well as uncertified TPRs.

Acknowledgments: This work is financially supported by the National Natural Science Foundation of China (Grant No. 71602186), Humanities and Social Sciences Youth Foundation of the Ministry of Education of China (Grant No. 15YJC630075), and the Science Foundation of China University of Petroleum, Beijing (No. 2462017BJB08, 2462015YQ1403, 2462014YJRC026).

Author Contributions: Huihui Liu conducted this research and built the game models; Xiaohang Yue provided insights and research guidance; Hui Ding and G. Keong Leong wrote the paper.

Conflicts of Interest: The authors declare no conflict of interest. 


\section{References}

1. Deng, Q.W.; Liu, X.H.; Liao, H.L. Identifying critical factors in the eco-efficiency of remanufacturing based on the fuzzy DEMATEL method. Sustainability 2015, 7, 15527-15547. [CrossRef]

2. Zhang, Z.Z.; Wang, Z.J.; Liu, L.W. Retail services and pricing decisions in a closed-loop supply chain with remanufacturing. Sustainability 2015, 7, 2373-2396. [CrossRef]

3. Guide, V.D.R.; Wassenhove, L.N. Managing product returns for remanufacturing. Prod. Oper. Manag. 2001, 10, 142-155. [CrossRef]

4. Li, J.; Du, W.H.; Yang, F.M.; Hua, G.W. Evolutionary game analysis of remanufacturing closed-loop supply chain with asymmetric information. Sustainability 2014, 6, 6312-6324. [CrossRef]

5. Lund, R.T. Remanufacturing. Technol. Rev. 1984, 87, 19-27.

6. Liu, H.H.; Lei, M.; Deng, H.H.; Leong, G.K.; Huang, T. A dual channel, quality-based price competition model for the WEEE recycling market with government subsidy. Omega 2016, 59, 290-302. [CrossRef]

7. Duygan, M.; Meylan, G. Strategic management of WEEE in Switzerland-Combining material flow analysis with structural analysis. Resour. Conserv. Recycl. 2015, 103, 98-109. [CrossRef]

8. Ferguson, M.E.; Toktay, L.B. The effect of competition on recovery strategies. Prod. Oper. Manag. 2006, 15, 351-368. [CrossRef]

9. Vadde, S.; Zeid, A.; Kamarthi, S.V. Pricing decisions in a multi-criteria setting for product recovery facilities. Omega 2011, 39, 186-193. [CrossRef]

10. Oraiopoulos, N.; Ferguson, M.E.; Toktay, L.B. Relicensing as a secondary market strategy. Manag. Sci. 2012, 58, 1022-1037. [CrossRef]

11. USITC (U.S. International Trade Commission). Remanufactured Goods: An Overview of the U.S. and Global Industries, Markets, and Trade; USITC Publication 4356; International Trade Commission: Washington, DC, USA, 2012.

12. Ferrer, G.; Swaminathan, J.M. Managing new and remanufactured products. Manag. Sci. 2006, 52, 15-26. [CrossRef]

13. Buying Refurbished Electronics, What You Need to Know: Is Buying a Refurbish TV Worth the Risk? Available online: http:/ / www.practical-home-theater-guide.com/refurbished-electronics.html (accessed on 25 January 2017).

14. HP Standard 007-2 Vendor Requirements for Hardware Recycling. Available online: http://www.hp.com/ hpinfo/globalcitizenship/environment/recycle/finalrecstds.pdf (accessed on 25 January 2017).

15. Lenovo United States Product Recycling Q\&A. Available online: https://www.lenovo.com/social_ responsibility/us/en/Lenovo_US_Product_Recycling.pdf (accessed on 25 January 2017).

16. Apple Plans China iPhone Trade-In Program with Foxconn. Available online: http://www. thanhniennews.com/tech/apple-plans-china-iphone-tradein-program-with-foxconn-40349.html (accessed on 25 January 2017).

17. Ni, D.; Li, K.W.; Tang, X. Social responsibility allocation in two-echelon supply chains: Insights from wholesale price contracts. Eur. J. Oper. Res. 2010, 207, 1269-1279. [CrossRef]

18. Tirole, J. Market Failures and Public Policy. Am. Econ. Rev. 2015, 105, 1665-1682. [CrossRef]

19. Xie, G. Cooperative strategies for sustainability in a decentralized supply chain with competing suppliers. J. Clean. Prod. 2016, 113, 807-821. [CrossRef]

20. Wei, Y.; Choi, T.M. Mean-variance analysis of supply chains under wholesale pricing and profit sharing schemes. Eur. J. Oper. Res. 2010, 204, 255-262. [CrossRef]

21. Xie, G. Modeling decision processes of a green supply chain with regulation on energy saving level. Comput. Oper. Res. 2015, 54, 266-273. [CrossRef]

22. Atasu, A.; Sarvary, M.; Van Wassenhove, L.N. Remanufacturing as a marketing strategy. Manag. Sci. 2008, 54, 1731-1746. [CrossRef]

23. Guide, V.D.R.; Li, J. The potential for cannibalization of new products sales by remanufactured products. Decis. Sci. 2010, 41, 547-572. [CrossRef]

24. Govindan, K.; Soleimani, H.; Kannan, D. Reverse logistics and closed-loop supply chain: A comprehensive review to explore the future. Eur. J. Oper. Res. 2015, 240, 603-626. [CrossRef]

25. Kumar, R.; Ramachandran, P. Revenue management in remanufacturing: Perspectives, review of current literature and research directions. Int. J. Prod. Res. 2016, 54, 2185-2201. [CrossRef] 
26. Mitra, S. Optimal pricing and core acquisition strategy for a hybrid manufacturing/remanufacturing system. Int. J. Prod. Res. 2016, 54, 1285-1302. [CrossRef]

27. Toktay, L.B.; Wein, L.M.; Zenios, S.A. Inventory management of remanufacturable products. Manag. Sci. 2000, 46, 1412-1426. [CrossRef]

28. Vlachos, D.; Georgiadis, P.; Iakovou, E. A system dynamics model for dynamic capacity planning of remanufacturing in closed-loop supply chains. Comput. Oper. Res. 2007, 34, 367-394. [CrossRef]

29. Bulmuş, S.C.; Zhu, S.X.; Teunter, R.H. Optimal core acquisition and pricing strategies for hybrid manufacturing and remanufacturing systems. Int. J. Prod. Res. 2014, 52, 6627-6641.

30. Mitra, S. Models to explore remanufacturing as a competitive strategy under duopoly. Omega 2016, 59, 215-227. [CrossRef]

31. Shi, J.M.; Zhang, G.Q.; Sha, J.C. Optimal production and pricing policy for a closed loop system. Resour. Conserv. Recycl. 2011, 55, 639-647. [CrossRef]

32. Souza, G.C.; Ketzenberg, M.E.; Guide, V.D.R. Capacitated remanufacturing with service level constraints. Prod. Oper. Manag. 2002, 11, 231-248. [CrossRef]

33. Zhou, Y.; Xiong, Y.; Li, G.D.; Xiong, Z.K.; Beck, M. The bright side of manufacturing-remanufacturing conflict in a decentralised closed-loop supply chain. Int. J. Prod. Res. 2013, 51, 2639-2651. [CrossRef]

34. Van Der Laan, E.; Salomon, M.; Dekker, R.; Wassenhove, L.V. Inventory control in hybrid systems with remanufacturing. Manag. Sci. 1999, 45, 733-747. [CrossRef]

35. Ferguson, M.; Guide, V.D.R.; Koca, E.; Souza, G.C. The value of quality grading in remanufacturing. Prod. Oper. Manag. 2009, 18, 300-314. [CrossRef]

36. Ferrer, G.; Whybark, D. Material planning for a remanufacturing facility. Prod. Oper. Manag. 2001, 10, 112-124. [CrossRef]

37. Galbreth, M.R.; Blackburn, J.D. Optimal acquisition and sorting policies for remanufacturing. Prod. Oper. Manag. 2006, 15, 384-392. [CrossRef]

38. Wu, C.H. OEM product design in a price competition with remanufactured product. Omega 2013, 41, $287-298$. [CrossRef]

39. Zou, Z.B.; Wang, J.J.; Deng, G.S.; Chen, H. Third-party remanufacturing mode selection: Outsourcing or authorization? Transp. Res. Part E 2016, 87, 1-19. [CrossRef]

40. Hong, X.P.; Govindan, K.; Xu, L.; Du, P. Quantity and collection decisions in a closed-loop supply chain with technology licensing. Eur. J. Oper. Res. 2017, 256, 820-829.

41. Huang, Y.T.; Wang, Z.J. Closed-loop supply chain models with product take-back and hybrid remanufacturing under technology licensing. J. Clean. Prod. 2017, 142, 3917-3927. [CrossRef]

42. Wang, K.Z.; Zhao, Y.X.; Cheng, Y.H.; Choi, T.M. Cooperation or competition? Channel choice for a remanufacturing fashion supply chain with government subsidy. Sustainability 2014, 6, 7292-7310. [CrossRef]

43. Vorasayan, J.; Ryan, S. Optimal price and quantity of refurbished products. Prod. Oper. Manag. 2006, 15, 369-383. [CrossRef]

(C) 2017 by the authors. Licensee MDPI, Basel, Switzerland. This article is an open access article distributed under the terms and conditions of the Creative Commons Attribution (CC BY) license (http:// creativecommons.org/licenses/by/4.0/). 